\title{
Adsorption of High Density Lipoproteins (HDL) on Solid Surfaces
}

\author{
Minhua Feng, $*$ Antonia Berdugo Morales, $*$ Tom Beugeling, ${ }^{*}, 1$ Adriaan Bantjes, $*$ Kees van der Werf, $\dagger$ \\ Guido Gosselink, $\dagger$ Bart DE Grooth, $\dagger$ AND Jan Greve $\dagger$
}

*Department of Chemical Technology and $\dagger$ Department of Applied Physics, University of Twente, P.O. Box 217, 7500 AE Enschede, The Netherlands

The adsorption of high density lipoproteins (HDL) on polyethylene (PE), poly (2-hydroxyethyl methacrylate) (poly(HEMA)), polyesterurethane (PU ), Biomer, and mica surfaces was studied. The adsorption of HDL from a single protein solution and a plasma solution on the surfaces showed that the amount of adsorbed HD L was not related to the hydrophobicity (or hydrophilicity) of the surfaces. It was observed that the amount of HDL adsorbed on PE increased with increasing HDL concentration of a single protein solution until $5 \mu \mathrm{g} / \mathrm{ml}$, and increasing plasma concentration resulted in an increase of HDL adsorption. In addition, HDL adsorption from an HDL solution of $500 \mu \mathrm{g} / \mathrm{ml}$ on PE reached a maximum within a few minutes at $25^{\circ} \mathrm{C}$. Only a proportion of adsorbed H DL could be desorbed when the adsorbed layers were incubated with Tween $\mathbf{2 0}$ or sodium dodecyl sulfate (SD S), while the desorption was dependent on the nature of the surfaces. It was more difficult to desorb HDL adsorbed from plasma to PE than to desorb HDL adsorbed from a single protein solution to PE. It was found that the desorption of adsorbed HDL from PE by the detergents was decreased if the protein layer had been stored in buffer ( $\mathrm{pH}$ 7.4) for $24 \mathrm{~h}$ before desorption, while a higher storing temperature had a negative effect on the desorption of the lipoprotein from the surface. Adsorbed HDL on mica in a physiological buffer was imaged by a tapping mode atomic force microscope (AFM). The surface appeared to be covered by single HDL proteins as well as clusters of two or three HDL proteins with an average height of 5 to $6 \mathrm{~nm}$. Furthermore, the partial desorption of adsorbed HDL from mica was confirmed by AFM measurements. 1996 Academic Press, Inc.

Key Words: protein adsorption; H D L; solid surfaces; desorption of HDL; AFM.

\section{INTRODUCTION}

High density lipoproteins (HDL) attract increasing attention because of epidemiological studies suggesting an inverse relationship between HDL concentration in plasma and the risk of coronary heart disease (CHD) $(1,2)$. It has been proposed (3) that HDL modulates the risk of premature cardiovascular disease by facilitating the removal of excess cholesterol from peripheral tissues and transporting the cho-

\footnotetext{
${ }^{1}$ To whom correspondence should be addressed.
}

lesterol back to the liver (reverse cholesterol transport (4)) or transferring cholesterol to very low density lipoproteins (VLDL) or low density lipoproteins (LDL) by the cholesteryl ester exchange protein.

An interesting observation was made in our laboratory (5-7), indicating that HDL preferentially adsorbs on hydrophobic polymer surfaces, resulting in a low adsorption of fibrinogen from plasma. In addition, the adsorption of selected lipid and lipoprotein components on heart valve prostheses after implantation in human beings has been reported earlier $(8,9)$. A decreased level of HDL has been observed in blood plasma of patients undergoing hemodialysis $(10,11)$. However, the adsorption of HDL on various solid surfaces has not been studied in detail. A better understanding of HDL adsorption will probably provide more information on the blood compatibility of biomaterials and the interpretation of the change of HDL concentration in plasma.

To establish whether a protein is adsorbed reversibly, desorption studies are generally necessary. However, few investigations have been performed regarding the desorption of HDL from solid surfaces (12). Therefore, the desorption of HDL in the presence of detergents was studied to provide more information about the stability of adsorbed HDL. Despite the numerous experiments conducted so far to study protein adsorption on surfaces, the molecular details of these interactions are still largely unclear. The lack of direct information about the spatial structure of the adsorbed proteins means that there are many aspects of protein adsorption that are not understood. Recently developed atomic force microscopy (AFM) (13) appears to be ideal for the direct study of adsorbed proteins in physiological buffer. The advantage of AFM is that it can simultaneously locate a site with nanometer accuracy and sense small forces on a surface, which makes it possible to detect biomolecular objects with molecular resolution.

The aim of this investigation was to study the adsorption of HDL on various solid surfaces as well as the reversibility of the adsorption, and to investigate the molecular details of the adsorbed proteins. In this study, the adsorption of HDL from a single protein solution and a plasma solution on polyethylene (PE), poly(2-hydroxyethyl methacrylate) 
(poly (HEMA)), polyesterurethane (PU), Biomer, and mica surfaces was determined, using a two-step enzyme-immunoassay. The reversibility of HDL adsorption was examined by investigating the desorption of adsorbed HDL from the surfaces by Tween 20 and sodium dodecyl sulfate (SDS). Furthermore, the adsorbed HDL on mice was imaged using an AFM with a tapping mode in buffer.

\section{MATERIALS AND METHODS}

\section{Reagents}

Phosphate buffered saline (PBS, $\mathrm{pH} 7.4$ ) was obtained from NPBI (Emmer-Compascuum, The Netherlands). Tween 20 and sodium dodecyl sulfate (SDS, purity > $99.0 \%$ ) were purchased from Sigma (St. Louis) and Merck (Darmstadt), respectively, and used without further purification. Tween and SDS solutions were prepared by dissolving Tween 20 or SDS in PBS (w/v).

A solution of human high density lipoproteins (HDL) was purchased from Sigma (St. Louis) and used without further purification. For the protein adsorption experiments, the stock solution containing $1000 \mu \mathrm{g} \mathrm{HDL} / \mathrm{ml}$ in PBS ( $\mathrm{pH} 7.4$ ) was prepared. Human blood plasma containing $21.7 \mathrm{mM}$ citrate (ACD plasma) was provided by the Blood Bank (Enschede, The Netherlands). Before use, the plasma was diluted to 1:500 (v/v) with PBS (pH 7.4).

Rabbit serum directed against human apolipoprotein AI (apo A-I) was provided by Behringwerke AG (Marburg) and was diluted to $1: 10$ with the first antibody buffer consisting of $150 \mathrm{mM} \mathrm{NaCl}, 50 \mathrm{~m} M$ Tris, $0.2 \%(\mathrm{w} / \mathrm{v})$ gelatin (Merck, Darmstadt), and $0.5 \%(\mathrm{w} / \mathrm{v})$ bovine serum albumin (BSA, Sigma), pH 7.5 before use. Sheep anti-rabbit IgG (the second antibody) conjugated to horseradish peroxidase was obtained from United States Biochemical Co. (Cleveland). The conjugate was diluted to 1:200,000 with a buffer which had the same composition as in the first antibody buffer except for a $5 \%(\mathrm{w} / \mathrm{v})$ bovine serum albumin.

The leuko dye solution consisted of $165 \mu \mathrm{l}$ of $3,3^{\prime}, 5,5^{\prime}-$ tetramethylbenzidine (Fluka AG, Buchs) solution in DMSO (Merck) $(6 \mathrm{mg} / \mathrm{ml})$ and $10 \mathrm{ml}$ of the acetate/citrate buffer ( $0.11 \mathrm{M}$ acetate), the $\mathrm{pH}$ of which had been adjusted to 5.5 by adding solid citric acid. Shortly before use, $10 \mu \mathrm{l}$ of $3 \%$ $\mathrm{H}_{2} \mathrm{O}_{2}$ solution as the enzyme substrate was added to the leuko dye solution.

\section{Solid Surfaces}

Low-density polyethylene sheets (PE) with a thickness of $0.05 \mathrm{~mm}$ were obtained from Talas (Ommen, The Netherlands) and the inner sides of the sheets were used. Polyesterurethane (PU) film was provided by Atochem (Bonn) and adsorption was performed on the inner side of the film. Freshly cleaved surfaces of mica were formed by cleavage with adhesive tape. Pieces of mica were fixed to the base of the test device with double-sided adhesive tape as described previously (5). Poly(2-hydroxyethyl methacrylate) (poly(HEMA)) was purchased from Aldrich (Steinheim, Germany) and a film of this material was prepared by applying $10 \mathrm{ml}$ of the poly (HEMA) solution $(4 \%(\mathrm{w} / \mathrm{v})$ in DMF) on the stainless steel plate device (5) to form a layer of polymer solution, and drying the layer in the air for $4 \mathrm{~h}$ before use. Biomer ( segmented polyether polyurethane) was kindly provided by Ethicon (Somerville, NJ). The Biomer was dissolved in $\mathrm{N}, \mathrm{N}$-dimethylacetamide $(4 \%(\mathrm{w} / \mathrm{v}))$. Biomer film was prepared in the same way as poly(HEMA) film except for being dried under fresh $\mathrm{N}_{2}$ overnight.

The water-contact angles of PE, PU, Biomer, poly(HEMA) and mica surfaces were measured using a captive bubble method as described by Andrade et al. (14). The surfaces were fixed on the measuring device by means of a double-sided adhesive tape. Five readings on different parts of each surface were averaged.

\section{Protein Adsorption}

The protein adsorption experiments were performed with test devices as described previously (5). The test surface area and the contents of each well of a test device were 0.9 $\mathrm{cm}^{2}$ and $800 \mu \mathrm{l}$, respectively. According to the procedure described by Poot et al. (5) and recently modified by us (12), the adsorption of proteins was performed in the above mentioned test devices, with the candidate surface at the bottom, by adding $200 \mu \mathrm{l}$ of PBS followed by $200 \mu \mathrm{l}$ of HDL solution or plasma solution. The adsorption time was taken $60 \mathrm{~min}$; then the test surface was washed with PBS $(4 \times 800 \mu \mathrm{l})$ and incubated with PBS $(400 \mu \mathrm{l})$ for another $60 \mathrm{~min}$.

In order to measure the surface concentration of adsorbed HDL, a two-step enzyme-immunoassay (EIA) was used (5$7,12)$. Each well of the test device was filled with $200 \mu \mathrm{l}$ of the first antibody solution and incubated for $1 \mathrm{~h}$. Then the wells were washed with PBS containing $0.005 \%(\mathrm{w} / \mathrm{v})$ Tween $(4 \times 800 \mu \mathrm{l})$. After incubation with $200 \mu \mathrm{l}$ of the conjugate solution ( second antibody) for $1 \mathrm{~h}$, the wells were washed with PBS $(2 \times 800 \mu \mathrm{l})$; then the Teflon upper part of the test device was replaced with a clean one. The surfaces were washed with PBS again $(2 \times 800 \mu \mathrm{l})$, and $200 \mu \mathrm{l}$ of the substrate/leuko dye solution was added to each well. The enzymatic color reaction was carried out in the dark for $30 \mathrm{~min}$ and was stopped by addition of $100 \mu \mathrm{l}$ of $2 \mathrm{M} \mathrm{H}_{2} \mathrm{SO}_{4}$. From each well, $250 \mu \mathrm{l}$ of the solution was removed for the determination of the absorbance at $450 \mathrm{~nm}$ with a multiscanner (Reader Micro Elisa System, Organon Teknika, Turnhout).

\section{Desorption of Adsorbed HDL from the Surfaces}

In the desorption experiments, the wells of the test device were washed with PBS $(4 \times 800 \mu 1)$ after protein adsorption 


\section{TABLE 1}

The W ater - C ontact Angles of V arious Surfaces

\begin{tabular}{lc}
\hline \multicolumn{1}{c}{ Surface } & Contact angles $\left({ }^{\circ}\right)$ \\
\hline PE & $94.7 \pm 0.6$ \\
PU & $59.3 \pm 0.6$ \\
Biomer & $36.0 \pm 0.4$ \\
Poly(HEMA) & $29.9 \pm 0.6$ \\
Mica & $14.4 \pm 0.5$ \\
\hline
\end{tabular}

(see above) and incubated for 60 min with $400 \mu \mathrm{l}$ of PBS containing $0.05 \%$ (w/v) Tween 20 or SDS (with only PBS for blank control). Then the solutions were removed and the wells were washed with PBS $(1 \times 800 \mu 1)$. The surface concentration of HDL after desorption was determined in the same way as mentioned above.

\section{AFM Studies of the Adsorbed HDL on Mica}

Atomic force microscopy (AFM) was performed with a homebuilt stand-alone AFM as described by van der Werf et al. (15). The bottom of the AFM fluid cell, a cover glass, was replaced with mica (thickness about 200 micrometer). For the measurements we used sharpened silicon nitride tips (Park Scientific Instruments, FWMS-06AU). A reference image was carried out with tapping mode AFM (16) on freshly cleaved mica in the liquid cell filled with $1000 \mu \mathrm{l}$ of PBS. Then $100 \mu \mathrm{l}$ of the PBS was removed and $100 \mu \mathrm{l}$ of the HDL solution ( $15 \mu \mathrm{g} / \mathrm{ml}$ in PBS ) was added into the fluid cell (final concentration of HDL in the cell was 1.5 $\mu \mathrm{g} / \mathrm{ml})$. The solution was incubated for $30 \mathrm{~min}$ at room temperature $\left(20^{\circ} \mathrm{C}\right)$. The cell was washed with PBS $(4 \times$ $1000 \mu \mathrm{l})$. The adsorbed HDL on mica in PBS $(1000 \mu \mathrm{l})$ was imaged by tapping mode AFM.

For some experiments, the following procedure was performed. After the PBS was removed, the HDL adsorbed on mica was incubated for $60 \mathrm{~min}$ at room temperature with SDS-containing PBS $(0.05 \%(\mathrm{w} / \mathrm{v}))$ by adding $1000 \mu \mathrm{l}$ of the solution into the cell. Then the SDS solution was exchanged for PBS $(1000 \mu \mathrm{l})$ and the HDL on the surface after this desorption procedure was imaged again with the AFM.

\section{RESULTS}

\section{The Water-Contact Angles of the Surfaces}

The adsorption of HDL on five surfaces with various hydrophilicities was investigated. The water-contact angles of polyethylene (PE), poly(2-hydroxyethyl methacrylate) (poly (HEMA)), polyesterurethane (PU), Biomer, and mica surfaces were measured by the captive bubble method; the data are listed in Table 1. PE was the most hydrophobic of the five surfaces, while mica was the most hydrophilic sur-
TABLE 2

Relative Surface Concentrations of HDL on Surfaces with D ifferent Hydrophobicity

\begin{tabular}{lcc}
\hline & \multicolumn{2}{c}{$A 450 \mathrm{~nm}^{a}$} \\
\cline { 2 - 3 } \multicolumn{1}{c}{ Surface } & Protein solution $^{b}$ & Plasma solution $^{c}$ \\
\hline PE & $0.616 \pm 0.036$ & $0.683 \pm 0.022$ \\
Poly(HEMA) & $0.556 \pm 0.061$ & $0.500 \pm 0.077$ \\
Mica & $0.129 \pm 0.020$ & $0.300 \pm 0.014$ \\
PU & $0.116 \pm 0.011$ & $0.107 \pm 0.008$ \\
Biomer & $0.128 \pm 0.007$ & $0.067 \pm 0.013$ \\
\hline
\end{tabular}

${ }^{a}$ All absorbance values (A $450 \mathrm{~nm}$ ) of the EIA are expressed as mean $\pm \mathrm{SD}(n=4)$.

${ }^{b}$ Concentration of $500 \mu \mathrm{g} / \mathrm{ml}$.

${ }^{c}$ Dilution of 1:1000.

face. PU, Biomer, and poly(HEMA) were intermediate, and their hydrophobicity was in the order $\mathrm{PU}>$ Biomer $>$ poly(HEMA).

\section{Relative Adsorption of HDL on Various Surfaces}

The adsorption of HDL on the surfaces was detected with a two-step enzyme-immunoassay. Because the EIA is a semiquantitative technique (7), only relative surface concentrations of HDL adsorbed on the surfaces could be determined. The relative surface concentrations of HDL on the surfaces with different hydrophobicities are given in Table 2. The amount of HDL adsorbed from both HDL and plasma solution on the surfaces was in the order PE $>$ poly (HEMA) $\gg$ Mica $\sim$ PU $\sim$ Biomer. In addition, significant differences between the amounts of HDL adsorbed from the plasma solution and the single protein solution were not observed under these conditions.

\section{HDL Adsorption as a Function of HDL Concentration}

The relative amounts of HDL adsorbed for $1 \mathrm{~h}$ from single protein solutions with various HDL concentrations on PE are given in Fig. 1. The adsorption of HDL increased with

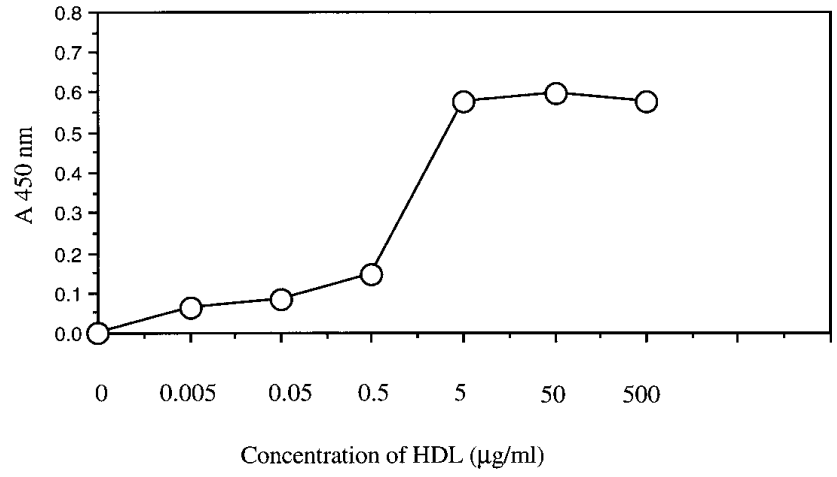

FIG. 1. Adsorption of HDL from HDL solutions $\left(25^{\circ} \mathrm{C}, 1 \mathrm{~h}\right)$ to $\mathrm{PE}$ as a function of the HDL concentration. 


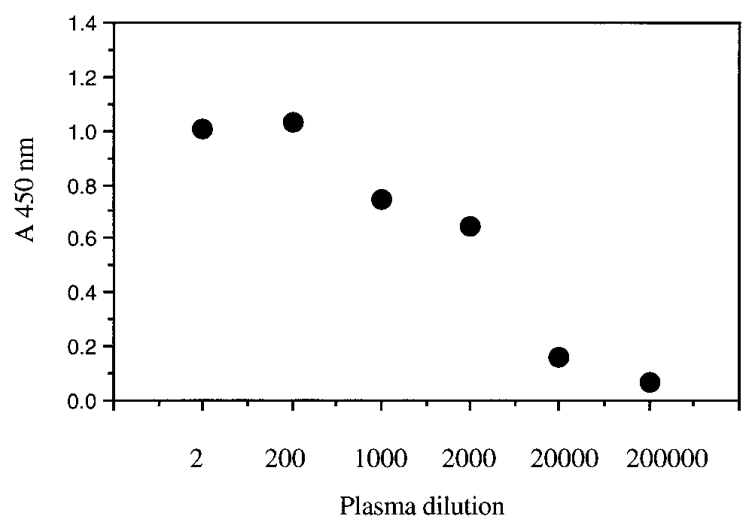

FIG. 2. The effect of plasma dilution on the adsorption of HDL from a plasma solution onto $\mathrm{PE}\left(25^{\circ} \mathrm{C}, 1 \mathrm{~h}\right)$.

increasing the HDL concentration from 0 to $5 \mu \mathrm{g} / \mathrm{ml}$, and reached a plateau value at a concentration above $5 \mu \mathrm{g} / \mathrm{ml}$.

\section{HDL Adsorption as a Function of Plasma Dilution}

Figure 2 shows the results of HDL adsorption on PE as a function of the plasma dilution (from 1:2 to 1:200000). A small plateau of HDL adsorption was found between plasma dilution 1:2 and 1:200; thereafter the adsorbed amount of HDL decreased with increasing plasma dilution.

\section{Effect of Temperature on the Adsorption of HDL}

The effect of temperature on HDL adsorption on PE was estimated using an HDL solution of $500 \mu \mathrm{g} / \mathrm{ml}$ and a plasma dilution of 1:1000 (Fig. 3). The amount of HDL adsorbed from the single protein solution was about the same at the two temperatures, while more HDL adsorbed at a higher temperature from the plasma solution.

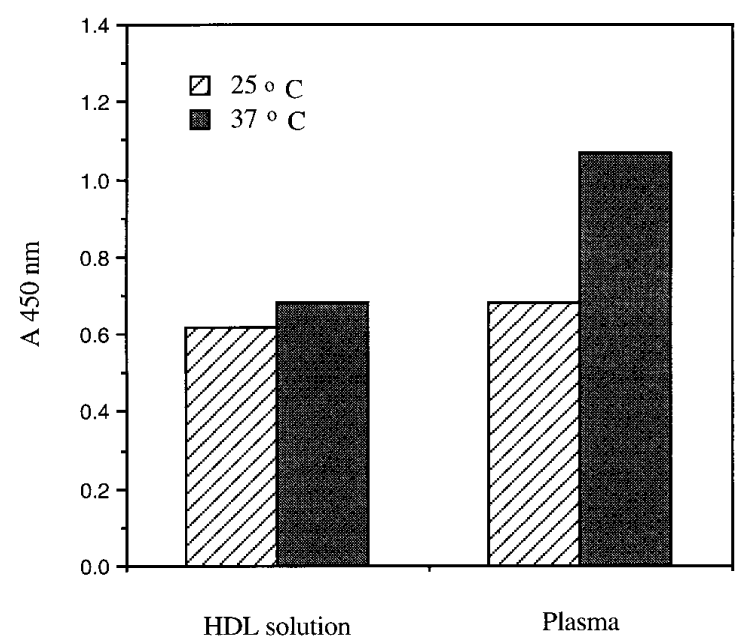

FIG. 3. HDL adsorption from an HDL solution and from a plasma solution on $\mathrm{PE}$ at 25 or $37^{\circ} \mathrm{C}$ for $1 \mathrm{~h}$.

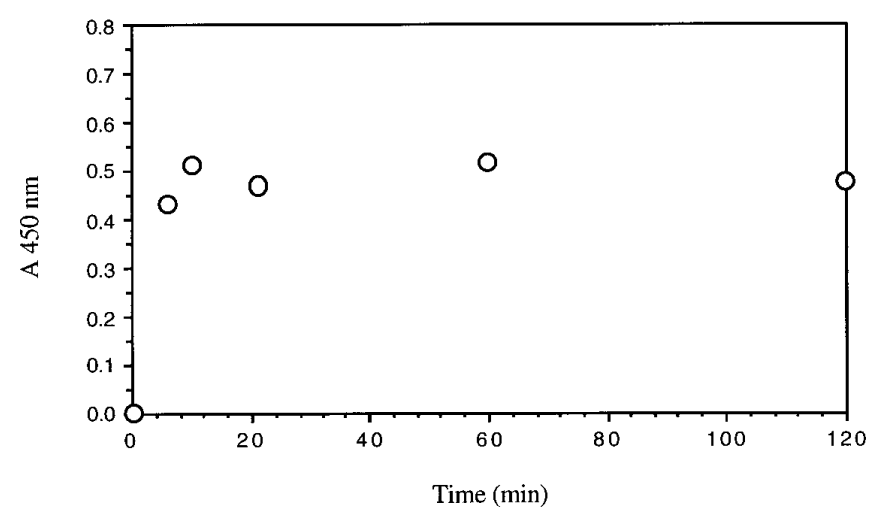

FIG . 4. Adsorption of HDL onto PE from an HDL solution $(500 \mu \mathrm{g} /$ $\mathrm{ml}$ ) as a function of time at $25^{\circ} \mathrm{C}$.

\section{Adsorption Kinetics of $H D L$}

HDL adsorption on PE from a single protein solution at $25^{\circ} \mathrm{C}$ was studied as a function of time (from 0 to $120 \mathrm{~min}$ ); the results are shown in Fig. 4. A significant increase of the amount of HDL as a function of time was observed within a few minutes and the adsorbed amount did not increase after that time, indicating that the adsorption of HDL reached a maximum within a few minutes.

\section{Desorption of HDL from the Surfaces}

Table 3 summarizes the results of HDL desorption by Tween 20 and SDS from various material surfaces. Under the conditions mentioned under $\mathrm{A}$, it was easy to desorb most of adsorbed HDL from PE, whereas it was difficult to desorb HDL from poly (HEMA). In addition, the desorption of adsorbed HDL from mica, PU and Biomer by Tween 20 was not effective. Comparing the desorption of HDL from $\mathrm{PE}$ at conditions of $\mathrm{A}$ and $\mathrm{B}$ indicates that it was more difficult to desorb HDL adsorbed from plasma than from a single protein solution. It was found that the desorption of HDL was lower when the adsorption and desorption took place at a higher temperature (C and D). This effect of temperature became more obvious when HDL had been adsorbed from plasma and the desorption was carried out with Tween.

\section{Effect of Storing Temperature on the Desorption of Adsorbed HDL}

The interaction strength between an adsorbed protein and a solid surface may change during storage in a buffer. Therefore the effect of the storing temperature on the desorption of adsorbed $\mathrm{HDL}$ from PE was explored at 25,37 , and $50^{\circ} \mathrm{C}$ (Fig. 5). It was found that the desorption of adsorbed HDL by Tween or SDS from PE was decreased if the protein layer had been stored in buffer $\left(\mathrm{pH} \mathrm{7.4)}\right.$ for $24 \mathrm{~h}$ at $25^{\circ} \mathrm{C}$ before the desorption procedure (see data in Table 3 and Fig. 5 ). Furthermore, if the storage temperature was higher, 


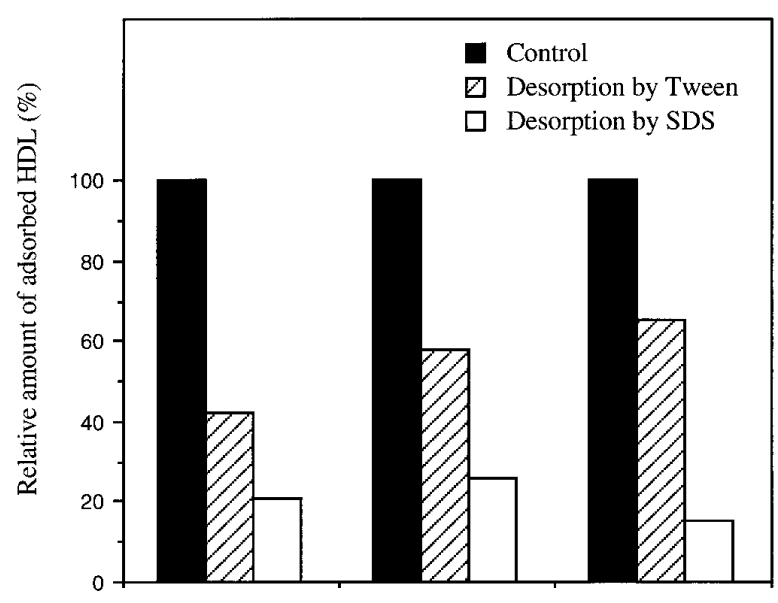

$25^{\circ} \mathrm{C}$

$37^{\circ} \mathrm{C}$

$50^{\circ} \mathrm{C}$

FIG. 5. The desorption of HDL from PE by Tween and SDS after the protein layer had been stored in buffer for $24 \mathrm{~h}$ at various temperatures.

the relative desorption of the protein was less except for the desorption by SDS at $50^{\circ} \mathrm{C}$.

\section{Adsorbed HDL on Mica Studied with AFM}

The adsorbed HDL on mica before and after desorption was investigated (Fig. 6) with the tapping mode AFM in buffer. In this mode the AFM tip vibrated above the sample. Only during a short period of the complete movement did the cantilever touch the sample. The damping caused by the tip-sample interaction can be used to measure the topography of the sample. Compared to the damage caused by lateral forces in the case of normal contact mode AFM, tapping mode AFM is much more gentle to soft samples. Figure 6A shows a background image of the freshly cleaved mica surface used for HDL adsorption experiments. This surface was extremely smooth, which is shown by its root mean square (RMS) roughness value of $0.1 \mathrm{~nm}$. This value is mainly determined by residual vibration of the whole set-up (inverted microscope with the fluid cell) and acoustic noise picked up by the thin mica sheet. In Fig. 6B the image of the adsorbed HDL measured under the same conditions is given. Using this HDL concentration the surface appeared to be covered by some single HDL protein molecules as well as clusters of two or three HDL proteins. The clusters have an average height of 6 to $7 \mathrm{~nm}$ and lateral dimensions of $60 \pm 10 \mathrm{~nm}$, while the single proteins have an average height of $5 \mathrm{~nm}$ and lateral dimensions of $30 \pm 10 \mathrm{~nm}$. Figure 6C gives the image of the surface after the adsorbed HDL had been incubated with a SDS solution. A significant proportion of adsorbed HDL was desorbed from the surface. The residual HDL particles that were observed had a height of about $5 \mathrm{~nm}$.

\section{DISCUSSION}

\section{HDL Adsorption}

HDL is known to be constituted of particles with heterogeneous size (17). The fraction of plasma lipoproteins with a density of $1.063-1.210 \mathrm{~g} / \mathrm{ml}$ has been operationally defined as high-density lipoproteins (HDL). Within this density range, the major HDL subfractions are $\mathrm{HDL}_{3}$ with a density range of $1.110-1.210 \mathrm{~g} / \mathrm{ml}$ and $\mathrm{HDL}_{2}$ with a density range of $1.063-1.110 \mathrm{~g} / \mathrm{ml}$.

The surface concentration of HDL adsorbed onto various surfaces was measured with an enzyme-immunoassay, which has the advantage of high sensitivity and specificity, making it possible to detect the apoprotein part of adsorbed HDL. Because of the immunochemical heterogeneity of the protein part, very specific antibodies directed against HDL do not exist. However, since apo A-I amounts to approximately $70 \%$ of the total amount of protein in HDL, and since this polypeptide seems to be present in most of the HDL subfractions (3), antiserum specific for apo A-I was used for the detection of HDL.

In a previous study (12) we found that the nonspecific adsorption of the first antibody as well as the conjugated second antibody, could be effectively eliminated by washing with PBS, containing $0.005 \%$ (w/v) Tween 20 . This procedure was also used in the present investigation ( see Materials and Methods).
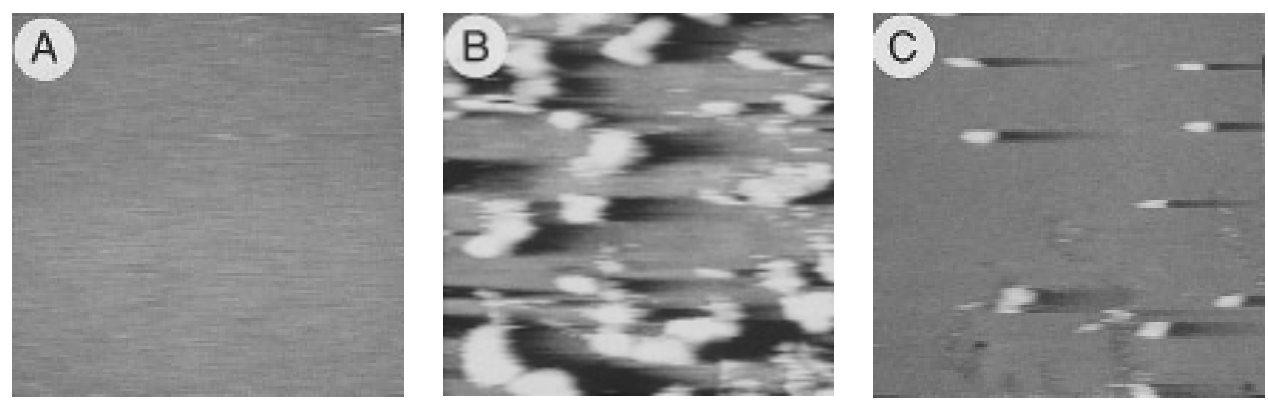

FIG. 6. AFM images of a mica surface (A), the adsorbed particles of HDL on mica (B), and the HDL particles adsorbed on mica after desorption by $\operatorname{SDS}(\mathrm{C})$. 
The adsorption data of the EIA are expressed as absorbances $(A 450)$ of the generated dye in the assays. These data are not directly related to the amounts of adsorbed protein $/ \mathrm{cm}^{2}$ for the following reasons. Protein molecules generally undergo conformational changes during and after adsorption. As a consequence several antigenic determinants of a protein molecule may lose their specific structure and may not be able to react with binding sites of the applied antibody. This phenomenon not only depends on the protein and the material surface, but also on the possibility of the protein to unfold and spread upon the surface, which is timedependent and influenced by the surface concentration of proteins already adsorbed. Moreover, in the case of multiple layer adsorption, sublayers cannot be detected by the EIA. Therefore a comparison of the data obtained by this technique with those of a quantitative method such as radiolabelling is very difficult (7).

Although no attempt was made to compare the adsorption of HDL on polyethylene and glass, Poot et al. (5) reported that HDL could preferentially adsorb on both substrates. However, van Damme et al. (7) observed a somewhat lower adsorption of HDL on two poly ( $n$-alkyl methacrylate) surfaces with contact angles of $48^{\circ}$ and $65^{\circ}$ compared to the adsorption on another poly ( $n$-alkyl methacrylate) surface with a contact angle of $73^{\circ}$. Those observations seem to indicate that a high adsorption of HDL on both hydrophilic and hydrophobic surfaces and a low adsorption of HDL on medium hydrophilic surfaces can be expected. In our study, solid surfaces with a wider range of surface hydrophilicities were chosen. As indicated in Table 1, the water-contact angles of the surfaces ranged from $14^{\circ}$ to $95^{\circ}$. We also found that HDL showed a high adsorption on hydrophobic surfaces such as PE and on hydrophilic surfaces such as poly(HEMA). On surfaces with a medium hydrophilicity such as PU and Biomer the adsorption of HDL was quite low. However, the HDL adsorption was also low on the very hydrophilic surface of mica. These results cannot be explained by the hydrophilicities of the surfaces, and in our opinion, to understand the adsorption of a protein on a surface, more properties of the protein and the surface, such as electrostatic interactions and hydrogen bond formation, may be important.

The adsorption of HDL onto PE was studied in more detail. The HDL adsorption increased with increasing HDL concentration from 0 to $5 \mu \mathrm{g} / \mathrm{ml}$. However, no more HDL adsorbed on the surface with HDL concentration above 5 $\mu \mathrm{g} / \mathrm{ml}$ (Fig. 1), which seems to indicate that $5 \mu \mathrm{g} \mathrm{HDL} / \mathrm{ml}$ solution was sufficient to form a monolayer of adsorbed HDL under the experimental conditions.

It was also observed that the adsorption of HDL from plasma increased as the plasma dilution decreased from 1:200,000 to 1:200 (Fig. 2). Because whole plasma generally contains $1 \mathrm{mg} / \mathrm{ml}$ of $\mathrm{HDL}$, the 1:200 diluted plasma should contain an HDL concentration of about $5 \mu \mathrm{g} / \mathrm{ml}$. This observation is completely consistent with the results shown in Fig. 1. Moreover, the results from Figs. 1 and 2 further confirm that HDL preferentially adsorbs onto solid surfaces $(5,6,7)$ because its adsorption was not influenced by the concentration change of other proteins in the plasma.

The kinetic data (Fig. 4) show that HDL adsorption reached a maximum within a few minutes, which is in agreement with the general observations that protein adsorption is an initial and fast process, and corresponds with the results on HDL adsorption mentioned in the literature (57 ). Higher temperature of the protein solution results in an increase of diffusion, displacement of other proteins from the surface, and conformation change of the adsorbed lipoprotein, which may result in a faster and stronger adsorption of the lipoprotein. The effect of temperature on the amount of adsorbed protein is complicated, but the adsorption of HDL from a plasma solution was found in our study to be higher at $37^{\circ} \mathrm{C}$ than at $25^{\circ} \mathrm{C}$.

\section{Desorption of $H D L$}

The stability of the adsorbed HDL on the surfaces was investigated by studying the desorption of HDL in the presence of Tween 20 and SDS. It was demonstrated that Tween 20 and SDS were able to desorb HDL from the surfaces, and SDS was more effective than Tween 20 (Table 3 ). These findings are in agreement with other studies. For example, Elwing et al. (18) showed that Tween 20 has a small effect on the desorption of adsorbed $\mathrm{Fb}$ and $\gamma$-globulin from hydrophilic surfaces. McGinlay et al. (19) observed that when the adsorbed layer of human IgG on poly (vinyl chloride) was incubated with Tween 20, a significant proportion $(\sim 60 \%)$ was desorbed from the surface, whereas SDS was able to desorb almost all of the fibrinogen adsorbed on polymer surfaces (20).

Bohnert et al. (21) and Elwing et al. (18) reported that desorption of proteins was inhibited to a large extent by incubating the adsorbed protein layer in buffer before desorption by detergents. This "residence time" effect has been explained by slow conformational and orientational changes of the adsorbed protein molecule, resulting in an increased number of contact points between the protein and the solid surface $(18,21)$. We also found that the desorption of HDL from PE by Tween 20 or SDS was reduced when the protein layer had been stored in buffer for $24 \mathrm{~h}$, and the "residence process"' was furthermore dependent on the temperature.

It is generally accepted that as the protein - surface interaction increases, the desorption of the adsorbed protein occurs with more difficulty (20). The interaction between a protein molecule and a surface is dependent on the nature of both the protein and the surface, such as hydrophobicity, charge density, electrostatic properties and hydrogen bond formation. Because the isoelectric points of HDL were found 
TABLE 3

\begin{tabular}{|c|c|c|c|c|}
\hline \multirow[b]{2}{*}{ Surface } & \multirow[b]{2}{*}{ Condition $^{b}$} & \multicolumn{3}{|c|}{ A $450 \mathrm{~nm}^{a}$} \\
\hline & & Control & $\begin{array}{l}\text { After desorption } \\
\text { by Tween }\end{array}$ & $\begin{array}{c}\text { After desorption } \\
\text { by SDS }\end{array}$ \\
\hline PE & A & $0.616 \pm 0.036$ & $0.133 \pm 0.056$ & $0.072 \pm 0.022$ \\
\hline Poly(HEMA) & A & $0.556 \pm 0.061$ & $0.398 \pm 0.022$ & $0.476 \pm 0.031$ \\
\hline Mica & A & $0.129 \pm 0.020$ & $0.157 \pm 0.014$ & $0.075 \pm 0.021$ \\
\hline $\mathrm{PU}$ & A & $0.116 \pm 0.011$ & $0.117 \pm 0.015$ & $0.071 \pm 0.009$ \\
\hline Biomer & A & $0.128 \pm 0.007$ & $0.129 \pm 0.006$ & $0.083 \pm 0.002$ \\
\hline PE & $\mathrm{B}$ & $0.683 \pm 0.022$ & $0.303 \pm 0.083$ & $0.072 \pm 0.039$ \\
\hline PE & $\mathrm{C}$ & $0.684 \pm 0.024$ & $0.198 \pm 0.050$ & $0.160 \pm 0.089$ \\
\hline PE & $\mathrm{D}$ & $1.066 \pm 0.068$ & $0.509 \pm 0.091$ & $0.094 \pm 0.015$ \\
\hline
\end{tabular}

${ }^{a}$ All absorbance values $(A 450 \mathrm{~nm})$ of the EIA are expressed as mean $\pm \mathrm{SD}(n=4)$.

${ }^{b}$ The conditions are defined as follows: (A) The adsorption experiments were carried out at $25^{\circ} \mathrm{C}$ for $1 \mathrm{~h}$ using an $\mathrm{HDL}$ solution (500 $\left.\mu \mathrm{g} / \mathrm{ml}\right)$, and the desorption was carried out with Tween or SDS $\left(0.05 \%\right.$ in PBS) for $60 \mathrm{~min}$ at $25^{\circ} \mathrm{C}$. (B) The conditions were the same as in (A), but the adsorption of HDL took place from a plasma solution (1:1000 dilution). (C) As in A, temperature $37^{\circ} \mathrm{C}$. (D) As in $\mathrm{B}$, temperature $37^{\circ} \mathrm{C}$.

to be in the range $\mathrm{pH} 3.8-5.2(22,23)$, it can be expected that the negatively charged HDL particles will strongly adsorb on $\mathrm{OH}$-containing surfaces such as poly (HEMA) as a result of hydrogen bond formation, and this may explain the quite low desorption of HDL from poly (HEMA).

According to the model of HDL proposed by Shen et al. (24), human HDL has a spherical core consisting of cholesterol esters and triglycerides which is surrounded by a monolayer of free cholesterol and phospholipids. The outer surface of the monolayer is covered with the apoproteins, which are closely packed together with the hydrophobic groups of phospholipids. Based on the structure of HDL and its negatively charged nature, it can be assumed that the outer surface of HDL is hydrophilic. This assumption may explain the facts that a high desorption from the hydrophobic surface of PE and a low desorption from more hydrophilic surfaces such as PU, Biomer, and mica were observed.

The mechanism of displacement of HDL from the surfaces by SDS or Tween 20 is quite uncertain due to the complexity of the systems. Apart from competition of the detergent and HDL for surface area, the detergent and HDL are probably able to form complexes both in bulk solution and at the interface. These complexes may either stabilize or destabilize the adsorbed HDL layer, resulting in adsorbed amounts of HDL which are higher or lower, respectively.

\section{Adsorbed HDL on Mica}

As mentioned above, HDL is a mixture of lipoprotein fractions differing not only in their lipid composition but also in their polypeptide content and distribution. High density lipoproteins are very small particles with an assumed spherical morphology, and therefore each particle consists of a number of molecules of proteins and lipids. It has been assumed that more than two-thirds of the surface of $\mathrm{HDL}_{2}$ is covered with proteins and less than one-third with lipids. In $\mathrm{HDL}_{3}$ more than $90 \%$ of the particle surface must be occupied by proteins. The available surface area, volume, and weight of an $\mathrm{HDL}_{2}$ particle permits four molecules of apo A-I, two of apo A-II, and one of apo C, together with 130 molecules of phospholipid and about 200 of cholesterol ( $80 \%$ esterified). In $\mathrm{HDL}_{3}$ the amount of apo A-I is reduced to two molecules per particle, and phospholipid and cholesterol to 50 molecules each. Most of the cholesterol, particularly the cholesterol esters, is buried in the lipophilic center of the HDL particles.

The recent development of atomic force microscopy allows to image adsorbed proteins in buffer and to investigate their presence on surfaces with high resolution and small deformation. The dimensions of human von Willebrand factor (25) and the adsorption of immunoglobulin $G$ and glucose oxidase (26) as a function of time have been studied by normal contact mode AFM. It was pointed out $(25,26)$, however, that on the hydrophilic surface of mica the contact mode AFM had produced images that display features obviously formed by the imaging process. These approaches did not reveal clear images of protein distribution formed by adsorption $(27,28)$. In our study the adsorbed HDL in buffer was imaged by tapping mode AFM to diminish negative effects such as deformation and destruction of soft biological molecules due to the high lateral forces in contact mode AFM.

In order to image HDL by AFM, a smooth substrate was needed so that protein molecules could be distinguished from the topographical features of the underlying surface. Mica fulfills this requirement. The mica surface is sufficiently smooth to permit identification of adsorbed HDL (Fig. 6). The signal to noise ratio of the whole set-up showed a mica surface with a RMS roughness value of $0.1 \mathrm{~nm}$. 
The adsorption of the lipoprotein can be visualized (Fig. 6B) after the mica has been incubated with the HDL solution for $30 \mathrm{~min}$. The surface appeared to be covered by some single HDL proteins as well as clusters of two or three HDL proteins. The average height of the adsorbed HDL was 5 to $6 \mathrm{~nm}$. Native HDL particles are assumed to have diameters ranging from 5 to $12 \mathrm{~nm}$ (29). It has been previously reported that the average dimensions were $9.5 \mathrm{~nm}$ and $6.5 \mathrm{~nm}$ for $\mathrm{HDL}_{2}$ and $\mathrm{HDL}_{3}$, respectively (30). Our results are in agreement with those values, and the lower average height was probably due to a slight deformation of the HDL particles.

Evidently, a significant proportion of adsorbed HDL had been removed from mica by SDS (Figs. 6B and 6C). After desorption, some separated particles still remained on the surface, with typical height $5 \mathrm{~nm}$ and size $30 \pm 10 \mathrm{~nm}$. However, because the adsorption and the scanning are dynamic processes, the images of the adsorbed HDL were not always the same. In addition, it should be indicated that the elliptical shape and apparent size of the proteins are dependent on the tip radius and the residual movement of the proteins in the scan direction. It has been pointed out by Vesenka et al. (31) that particles appear broadened in AFM because of the finite size of the tips. From simple geometric arguments one can show that $W=4 \times\left(R_{\mathrm{c}} R_{\mathrm{m}}\right)^{1 / 2}$, where $W$ is the estimated width, $R_{\mathrm{c}}$ is the radius of curvature of a parabolic tip, and $R_{\mathrm{m}}$ is the radius of the particle. With a typical radius of curvature of $20 \mathrm{~nm}$, the apparent size of proteins with a diameter of $5-12 \mathrm{~nm}$ will be $30-45 \mathrm{~nm}$. This is in good agreement with the apparent size of HDL particles measured here.

\section{CONCLUSIONS}

HDL adsorbs from a single protein solution and a plasma solution on PE, poly (HEMA), PU, Biomer, and mica surfaces. The relative adsorption on these surfaces was not related to the hydrophobicity (or hydrophilicity) of the surfaces. The HDL adsorption on PE showed that the adsorbed amount was dependent on the HDL concentration, temperature, and time.

It was demonstrated that adsorbed HDL was desorbed to a large extent by Tween 20 and SDS, depending on the nature of the surfaces, and SDS was more effective than Tween 20. If the protein layer had been stored in buffer the desorption of HDL from PE was reduced.

The adsorbed HDL on mica was directly visualized with AFM, and the desorption of the adsorbed HDL from mica was also clearly observed. Single HDL proteins as well as clusters of two or three HDL proteins adsorbed on mica were observed with the AFM.

\section{ACKNOWLEDGMENTS}

The authors appreciate the assistance of Mrs. I. Seegers for the analysis with AFM. Dr. A. Poot is gratefully acknowledged for discussion.

\section{REFERENCES}

1. Miller, N. E., and Miller, G. J., in "Clinical and Metabolic Aspects of High Density Lipoproteins,'” pp. $1-459$ (N. E. Miller and G. J. Miller, Eds.). Elsevier, New York, 1984.

2. Mussoni, L., Maderna, P., Camera, M., Bernini, F., Sironi, L., Sirtori, M., and Tremoli, E., Fibrinolysis 4(Suppl. 2), 79 (1990).

3. Brewer, B. H., Jr., and Rader, D. J., Prog. Lipid Res. 30, 139 (1991).

4. Glomset, J. A., J. Lipid Res. 9, 155 (1968).

5. Poot, A., Beugeling, T., van Aken, W. G., and Bantjes, A., J. Biomed. Mater. Res. 24, 1021 (1990).

6. Breemhaar, W., Brinkman, E., Ellens, D. L., Beugeling, T., and Bantjes, A., Biomaterials 5, 269 (1984).

7. Van Damme, H. S., Beugeling, T., Ratering, M. T., and Feijen, J., J. Biomater. Sci. Polym. Edn. 3, 69 (1991).

8. Carmen, R., and Mutha, S. C., J. Biomed. Mater. Res. 6, 327 (1972).

9. Chin, H. P., Harrison, E. C., Blankenhorn, D. H., and Moacanin, J., Circ. (Suppl. 1) 53, 151 (1971).

10. Bagdad, J. D., and Alberts, J. J., N. Engl. J. Med. 296, 1436 (1977).

11. Levine, J., Falk, B., Henriquez, M., Raja, R. M., Kramer, M. S., and Rosenbaum, J. L., Trans. Am. Soc. Artif. Intern. Organs 24, 43 (1978).

12. Feng, M., Berdugo Morales, A., Poot, A., Beugeling, T., and Bantjes, A., J. Biomater. Sci. Polym. Edn. 7, 415 (1995).

13. Binning, G., Quate, C. F., and Gerber, C., Phys. Rev. Lett. 56, 930 (1986).

14. Andrade, J. D., King, R. N., Gregonis, D. E., and Coleman, D. L., J. Polym. Sci. Polym. Symp. 66, 313 (1979).

15. van der Werf, K., Putman, C., de Grooth, B., van Hulst, N., and Greve, J., Rev. Sci. Instrum. 64, 2892 (1993).

16. Putman, C., van der Werf, K., de Grooth, B., van Hulst, N., and Greve, J., Appl. Phys. Lett. 64, 2454 (1994).

17. Eisenberg, S., J. Lipid Res. 25, 1017 (1985).

18. Elwing, H., Askendal, A., and Lundstrom, I., J. Colloid Interface Sci. 128, 296 (1989).

19. McGinlay, P. B., and Bardsley, W. G., Biochem. J. 261, 715 (1989).

20. Slack, S. M., and Horbetl, T. A., J. Biomed. Mater. Res. 26, 1633 (1992).

21. Bohnert, J. L., and Horbett, T. A., J. Colloid Interface Sci. 111, 363 (1986).

22. Ayrault-Jarrier, M., Levy, G., Wald, M., and Polanowsky, J., Bull. Soc. Chim. Biol. 45, 349 (1963).

23. Sundaram, G. S., Sodhi, H. S., and Mackenzie, S. L., Proc. Soc. Exp. Biol. Med. 141, 842 (1972).

24. Shen, B. W., Scanu, A. M., and Kezdy, F. J., Proc. Natl. Acad. Sci. USA 74, 837 (1977).

25. Siedlecki, C. A., Eppell, S. J., and Marchant, R. E., J. Biomed. Mater. Res. 28, 971 (1994).

26. Cullen, D. C., and Lowe, C. R., J. Colloid Interface Sci. 166, 12 (1994)

27. Marchant, R. E., Lea, A. S., Andrade, J. D., and Bockenstedt, P., J. Colloid Interface Sci. 148, 261 (1992).

28. Lea, A. S., Pungor, A., Hlady, V., Andrade, J. D., Herron, J. N., and Voss, E. W., Jr., Langmuir 8, 68 (1992).

29. Gurr, M. I., and Harword, J. L., ' 'Lipid Biochemistry,' 4th ed. Chapman \& Hall, London, 1991.

30. Forte, T. M., and Nordhausen, R. W., Methods Enzymol. 128 (Plasma Lipoproteins, Pt. A), 442 (1986).

31. Vesenka, J., Guthold, M., Tang, C. L., Keller, D., Delaine, E., and Bustamante, C., Ultramicroscopy 42-44, 1243 (1992). 